\title{
Innovative Approaches for the Complexity of Fibromyalgia
}

\section{Kim Lawson*}

Biomedical Research Centre, Sheffield Hallam University, Sheffield, UK

Fibromyalgia (FM) is a chronic condition that presents with a complex of symptoms that include widespread pain, fatigue, dysfunctional sleep and cognitive disruption [1]. The prevalence of this condition is reported to be $2-4 \%$ of the population in developed countries, increasing to greater than $7 \%$ of those over 70 years of age. As a consequence this presents as a major financial and social burden to patients with FM, their families and carers, and to healthcare systems. FM was classified by the American College of Rheumatology (ACR) in 1990 as widespread pain for at least 3 months and tenderness in at least 11 of 18 defined tender points [2]. The ACR criteria recognise patients with severe pain symptoms, but fail to assess the other symptoms and fulfilment for diagnosis has been suggested to miss $46 \%$ of patients with FM [3]. The subjective nature of the tender-point requirement has therefore led to its omission in the current 2010 ACR diagnostic criteria [4]. Significant progress in the understanding of the pathophysiology and identification of effective treatments of FM has been made recently $[1,5]$. FM is described as a condition of heightened generalized sensitization to sensory input presenting as a complex of symptoms, including pain, where the pathophysiology could include dysfunction of the CNS pain modulatory systems, dysfunction of the neuroendocrine system, and dysautonomia [1,5]. A primary pathophysiological mechanism involves excessive nociceptive neurotransmitter function in the ascending pain signaling pathway in the central nervous system accompanied by a dysfunction in the descending modulatory pathway between the brain and the dorsal horn of the spinal [5].

Current management approaches of improving health status in FM use a rehabilitation model, rather than a classic biomedical model, integrating exercise, education (stress management programs, Cognitive Behavioral Therapy (CBT)) and pharmacological treatment [6]. Although recommendations (e.g., European League Against Rheumatism (EULAR), American Pain Society (APS)) for FM management have been published [7,8], a universally accepted treatment algorhythm or approach is often lacking. Although a variety of treatment modalities have demonstrated an improvement in health status in a proportion of patients with FM in clinical trials, they are often limited. FM appears to affect a heterogenous group of patients who can differ with regard to the symptoms and also in their physical and psychological characteristics $[9,10]$. As a consequence treatment directed towards FM is highly variable and long-term prospective observational studies have found that outcomes are typically poor.

Currently only three medications for the treatment of FM are FDA approved, pregabalin, duloxetine and milnacipran $[1,5]$. Pharmacological treatment is often focused to the modulation of the neurotransmitters serotonin, noradrenaline, opioids, glutamate and substance $\mathrm{P}$, further supporting a central component in the pathophysiology of FM. The role of serotonin and noradrenaline in the descending inhibitory pathways has led to a focus of the use of re-uptake inhibitors as a therapeutic approach [1,5,11]. Greater efficacy has been observed with drugs that inhibit the re-uptake of both neurotransmitters (with an emphasis towards serotonin; e.g., amitriptyline, duloxetine) relative to selective serotonin (e.g., fluoxetine, citalopram) or noradrenaline (e.g., esreboxetine) re-uptake inhibitors although the latter remain an option for FM treatment $[1,5,11]$. The $\alpha 2 \delta$ ligand pregabalin probably achieves benefit by targeting glutamate and substance P disturbances. However due to inconsistent success of the aforementioned treatments within the FM patient population a number of novel targets have gained interest, leading to clinical trials of GABA receptor agonists (sodium oxybate), dopamine agonists (pramipexole, tergulide), NMDA receptor antagonists (ketamine, dextromethorphan), cannabinoid agonists (nabilone) and potassium channel activation (flupirtine) $[1,5,11]$.

The complexity of fibromyalgia is currently limiting success with pharmacological treatments; however novel targets and innovative approaches are being considered which could provide important clues to the further understanding of the pathophysiology of this condition.

\section{References}

1. Lawson K (2008) Treatment options and patient perspectives in the management of fibromyalgia: future trends. Neuropsychiatr Dis Treat 4: 10591071.

2. Wolfe F, Smythe HA, Yunus MB, Bennett RM, Bombardier C, et al. (1990) The American College of Rheumatology 1990 Criteria for the Classification of Fibromyalgia. Report of the Multicenter Criteria Committee. Arthritis Rheum 33: 160-172.

3. Katz RS, Wolfe F, Michaud K (2006) Fibromyalgia diagnosis: a comparison of clinical, survey, and American College of Rheumatology criteria. Arthritis Rheum 54: 169-176.

4. Wolfe F, Clauw DJ, Fitzcharles MA, Goldenberg DL, Häuser W, et al. (2011) Fibromyalgia criteria and severity scales for clinical and epidemiological studies: a modification of the ACR Preliminary Diagnostic Criteria for Fibromyalgia. J Rheumatol 38: 1113-1122.

5. Mease PJ, Dundon K, Sarzi-Puttini P (2011) Pharmacotherapy of fibromyalgia Best Pract Res Clin Rheumatol 25: 285-297.

6. Goldenberg DL, Bradley LA, Arnold LM, Glass J, Clauw D (2008) Understanding fibromyalgia and its related disorders. Prim Care Companion J Clin Psychiatry 10: 133-144

7. Burckhardt DC, Goldenberg D, Crofford L (2005) Guideline for the management of fibromyalgia syndrome pain in adults and children. In: APS Clinical Practice Guidelines Series. No 4. American Pain Society, Glenview, IL, USA.

8. Carville SF, Arendt-Nielsen S, Bliddal H, Blotman F, Branco JC, et al. (2008) EULAR evidence-based recommendations for the management of fibromyalgia syndrome. Ann Rheum Dis 67: 536-541.

9. Thieme K, Turk DC, Flor H (2004) Comorbid depression and anxiety in fibromyalgia syndrome: relationship to somatic and psychosocial variables. Psychosom Med 66: 837-844.

10. Turk DC, Okifuji A, Sinclair JD, Starz TW (1996) Pain, disability, and physical functioning in subgroups of patients with fibromyalgia. J Rheumatol 23: 1255 1262.

11. Ablin JN, Buskila D (2013) Fibromyalgia syndrome--novel therapeutic targets Maturitas 75: 335-340.

*Corresponding author: Dr. Kim Lawson, Department of Biosciences Biomedical Research Centre, Sheffield Hallam University, Faculty of Health and Wellbeing, City Campus, Sheffield, S1 1WB, UK, Tel: +44 (0)114 225 3057; E-mail: K.Lawson@shu.ac.uk

Received December 15, 2013; Accepted December 16, 2013; Published December 23, 2013

Citation: Lawson K (2013) Innovative Approaches for the Complexity of Fibromyalgia. Clin Exp Pharmacol 3: e126. doi:10.4172/2161-1459.1000e126

Copyright: (๑) 2013 Lawson K. This is an open-access article distributed under the terms of the Creative Commons Attribution License, which permits unrestricted use, distribution, and reproduction in any medium, provided the original author and source are credited. 